\title{
Is it Justified to use the Lapse Day as a Decision Maker of Laparoscopic Cholecystectomy for Symptomatic Gall Bladder Stone Disease
}

\section{Yu-Chung Chang*}

Department of Surgery, Masuda Medical Association Hospital, Toodacho, Masuda, Shimane, Japan

\begin{abstract}
Aim: Lapse from symptom onset to surgery has been traditionally used for the operation timing of cholecystectomy. However, intraoperative gallbladder (GB) inflammation status has never been studied to verify its justification.

Methods: Meticulous intraoperative inflammation status of 260 consecutive laparoscopic cholecystectomy (LC) patients with symptomatic GB stone disease was prospectively graded (I-VI). Inflammation status in terms of lapse, incidence of difficult GB, complication and conversion rate from LC to open cholecystectomy was retrospectively analysed.

Results: Various inflammation grades were non-significantly different in each lapse group irrespective of the lapse time. Severity is not always proportionally increased to the lapse time in every patient. One hundred seventeen patients $(45 \%)$ had inflammations beyond the GB that reached Calot's triangle or the hepatoduodenal ligament (Grade IV VI): $64(54.7 \%)$ were Grade V or VI and were defined as difficult GB. There were no statistically significant differences in terms of incidence of difficult GB, or conversion rate between the lapse groups. When divided into any two lapse groups, only the $\leq 3$ and $>3$ days groups showed a significant difference $(P=0.039)$ in the incidence of difficult $G B$. But the conversion rate was not significantly different $(P=0.388)$.

Conclusion: A majority of the patients were easily manageable despite the different lapse times. Less than onethird of the patients with difficult GB needed earlier LC to avert subsequent progression of dense fibrosis if delayed. Dichotomized lapse determination for LC without considering intraoperative inflammation status is not justified.
\end{abstract}

Keywords: Laparoscopic cholecystectomy; Cholecystitis; GB stone; Surgical timing; Bile duct injury; Inflammation grading

\section{Introduction}

During the past several decades, emergency cholecystectomy for acute, symptomatic cholecystitis had been prohibited when delayed over 72 hours (golden time rule). Interval elective cholecystectomy has been recommended for these cases. Since 1980, early surgery [1] (within 7 days [2,3]) has been advocated by randomized studies [4,5]; nevertheless, some surgeons still follow the golden time rule and advocate interval cholecystectomy in the era of laparoscopic cholecystectomy (LC). Now, early LC $(<72$ hours [4] or $<1$ week [5]) is recommended in these meta-analyses for a shorter hospital stay, lower hospital costs, averting readmission attributable to recurrent acute cholecystitis, and reducing the morbidity associated with delayed LC. However, the optimal treatment policy in patients with acute symptoms for more than a week is still controversial and unclear.

In the current debate about the optimal timing of LC, the cited data depend solely on indirect evidence, such as operation time, technical difficulty, and conversion rate. There is a need to obtain direct evidence, namely, detailed intraoperative findings of inflammation status in terms of different lapse periods, and to retrospectively determine reasonable timing for surgery based on the inflammation status around the gallbladder (GB), Calot's triangle, and the common bile duct (CBD) during LC. Since 1996, the author has been developing a grading system [6] for this purpose. This is the first report on using this grading system to provide intraoperative records of GB inflammatory status for reappraising and further clarifying the optimal timing for LC.

\section{Materials and Methods}

The author often encountered inflammation, from mild edema and swelling (constituting simple acute cholecystitis) to more severe disease with empyema, gangrene, necrosis, fibrosclerosis, or fistula changes, while doing LC. Severe inflammation or densely fibrotic changes of Calot's triangle and the hepatoduodenal ligament (HDL) can prevent a safe LC and predispose a patient to CBD injury, which is like a land mine for both the LC surgeon and patient. To prevent CBD injury, based on the technical difficulty and applicable data, this inflammation of the GB vicinity was simplified and classified into the GB area (Grades I-III), which is unrelated to a safe LC; Calot's triangle (Grades IV and V), which is critical to CBD injury when in a densely fibrotic state (Grade V); and the HDL area (Grade VI) in a frozen or fibrotic state, because of which LC was almost impossible. Grades V and VI are defined as a "difficult GB". The updated GB inflammation grading system is summarized in (Table 1): grade VI was added for HDL involvement.

A prospective, non-randomized, cross-sectional study that included 260 consecutive LCs on patients with symptomatic GB inflammation or gallstone disease (Table 2) was conducted solely by the author. The timing from acute onset to surgery (lapse time) was assumed to be the most important determinant for these inflammatory changes and was meticulously recorded for each patient. The patients were further divided into 7 lapse groups for the purpose of reappraising the so called "golden time rule" and the current trend of "LC $<1$ week" policies with other periods; two periods per week (1-3, 4-7, 8-10, and 11-14 days) for the first 2 weeks; then one period per week for the next 2 weeks; and the

*Corresponding author: Yu-Chung Chang, Department of Surgery, Masuda Medical Association Hospital, Todacho, Masuda, Shimane 699-3676, Japan, Tel: +81-856-22 3611, ext. 263; Fax: +81-856-22-0407; E-mail: changmdphd@yahoo.com

Received February 15, 2017; Accepted February 23, 2017; Published March 01,2017

Citation: Chang YC (2017) Is it Justified to use the Lapse Day as a Decision Maker of Laparoscopic Cholecystectomy for Symptomatic Gall Bladder Stone Disease. Hepatol Pancreat Sci 1: 105

Copyright: @ 2017 Chang YC. This is an open-access article distributed under the terms of the Creative Commons Attribution License, which permits unrestricted use, distribution, and reproduction in any medium, provided the original author and source are credited. 


\begin{tabular}{|c|c|}
\hline Grade & Characteristics \\
\hline 1 & None to slight gall bladder inflammation and wall thickening. \\
\hline II & Moderate gall bladder inflammation and wall thickening. \\
\hline III & Severe gall bladder inflammation and wall thickening. \\
\hline IV & $\begin{array}{l}\text { Mild to moderate inflammation or fibrosis involving Calot's triangle. } \\
\text { Slightly to moderately difficult to separate the structures, but they are } \\
\text { identifiable. }\end{array}$ \\
\hline V & $\begin{array}{l}\text { Severe inflammation or fibrosis involving Calot's triangle; very difficult } \\
\text { to separate and identify structures. }\end{array}$ \\
\hline VI & $\begin{array}{l}\text { Severe inflammation or fibrosis involving the hepatoduodenal } \\
\text { ligament or common bile duct; phlegmon, necrosis, fibrosis. }\end{array}$ \\
\hline
\end{tabular}

Table 1: Chang's grading of gall bladder and vicinity inflammation for laparoscopic cholecystectomy.

final group of more than one month (Table 3 and Figure 1). These data of inflammation grading were collected to analyse the suitable timing of an LC from the acute onset of the symptom (Tables 3-5).

Most of our patients were operated on relatively late (Table 3) for various reasons. Some patients were unaware of the necessity of surgery or reluctant to undergo surgical treatment, some required a timeconsuming thorough diagnosis and treatment for biliary pancreatitis or cholangitis with CBD stones, some had to wait until gastrointestinal physicians had stabilized their acute or septic episode, and some with or without a relapse were refused immediate surgery and scheduled by other surgeons for an interval cholecystectomy. The author's principle is to do an LC when consulted, regardless of the timing of acute onset, if the patient's hemodynamic condition is stable or stabilized by biliary drainage. When Calot's triangle was densely fibrotic and the cystic duct or CBD could not be identified, the LC was converted to an open cholecystectomy (OC) in order to avoid possible bile duct injury. Methods of dome-down manipulation, [7] "critical angle identification" (defined by the author as a medial angle of the Hartmann pouch of the GB and cystic duct), medial and lateral rotation of the infundibulum to expose Calot's triangle (the "flag technique"), [8] and open infundibulum to check the cystic duct orifice from inside the GB were used with difficult GB cases before severing the cystic duct or conversion to OC. All patients were fully informed of their conditions and consented to a possible conversion to OC before surgery. Postoperative complications were graded thus: Grade 0: no complication; Grade 1: non-bile related; Grade 2: bile-related but not needing intervention; Grade 3: bile-related and needing endoscopic nasobiliary drainage (ENBD) decompression; Grade 4: CBD injury.

Abdominal-wall-lifting LC was exclusively used in the current series and was prepared in accordance with the method of Nagai et al. [9] Acute or chronic cholecystitis was classified according to a pathological diagnosis of the GB specimens. Statistical comparisons were done using a Fisher exact test.

\section{Results}

Most of the acutely inflamed tissue in all the different lapse groups was not densely fibrotic (<grade IV) (Figure 1). In some patients with severe inflammation, such as GB empyema (21/26 cases), or gangrenous or necrotic GB ( $7 / 13$ cases), and Calot's necrosis (3/4 cases), the structures in the Calot's triangle area were still soft and identifiable, and LC was feasible with careful manipulation. But all 6 fibrotic changes in the HDL cases (grade VI, $\mathrm{n}=26$ ) required OC (Tables 2 and 3).

The overall conversion rate and incidence of difficult. GB (Grades $\mathrm{V}+\mathrm{VI})$ for the current series were 6.9\% (18/260) and 24.6\% (64/260), respectively. There were no significant differences in conversion rates or the incidence of difficult GB in each lapse group (Table 3). However, when all the patients were divided into two groups at each lapse point, a significant difference $(\mathrm{P}=0.039)$ in the incidence of difficult $\mathrm{GB}$ (Table 4 ) was shown, but only between the $\leq 3$ vs. $>3$ days lapse groups. The conversion rate was not significantly different for any lapse points (Table 5). Although not significantly different, operation difficulty was encountered in the $\geq 15$ days lapse group, and three CBD injuries $(1.15 \%)$ occurred on lapse days 15,21 , and 107 , respectively.

Current data demonstrate that each inflammation grade (I-VI) existed in each lapse group, and that a majority of cases (grades 1-IV) were easily manageable (62-96\%), especially in the $\leq 3,22-28$, and $>29$ days groups (Figure 1). Even in lapse groups longer than 7 days, which is beyond the current surgical criteria, inflammation grading patterns may not be worse than in the 4-7 days lapse group and immediate LC is not contraindicated. The grade with $\geq 29$ days lapse group showed that a majority of cases $(81 \%)$ were easily managed with LC as well (Figure 1). Current "time-based" surgical timing determination may not be justified.

In all, there were 33 cases $(12.7 \%)$ with complications (Figure 2) 12 non-bile-related (4.6\%), 10 minor bile-related (3.8\%), 8 major bile-related (3.1\%, needed ENBD), and 3 CBD injuries (1.15\%). More patients in the 4-7 days lapse group had bile leakage problems that needed ENBD decompression. There were two CBD injuries in the 1521 days lapse group and one fatal CBD injury on lapse day 106. The latter patient, for whom surgeons had refused 3 times to schedule an operation, underwent percutaneous GB drainage while waiting for a chance of interval cholecystectomy. She finally needed an emergency LC while she was in a septic condition. She died from CBD and right hepatic artery injuries (overall mortality rate: $0.39 \%$ ). CBD necrosis was noticed during the hepaticojejunostomy reconstruction. This is the surgical land mine by the delayed, interval cholecystectomy. Inflammation may not cease after the interval period.

\section{Discussion}

Cool down and delayed interval LC policy is not always a panacea: Before 1980, conservative therapy dominated the treatment of acute cholecystitis because of an unacceptable rate of erroneous diagnoses, [10] of bacterial contamination and the risk of septic complications that increased with the length of the case history, [11] after 1 week, the acute stage became subacute with the formation of abscesses and necrosis in the wall of the gallbladder, which resulted in technical intraoperative difficulties [12]. Therefore, immediate surgery and surgery delayed for more than 1 week were opposed.

In the era of LC, early LC ( $<1$ week) is recommended by metaanalytical studies $[4,5]$ for a short hospital stay, a quick return to work, fewer analgesics used, and no increase in morbidity compared with delayed LC. Currently, there is less discrepancy for early LC when the symptoms last for less than 1 week; however, most of the articles on surgery done on patients with symptoms lasting more than a week reported greater than normal technical difficulties [12,13] and longer hospital stays [2,5]. Interval cholecystectomy has been advocated $[14,15]$ and done [16,17] for the latter group; however, a planned interval cholecystectomy 4 to 8 weeks after the onset of acute symptoms with the hope of operating when the acute inflammation has abated is no longer supported, [17] and 23-35\% of repeat admissions for emergency cholecystectomy $[2,4,5]$ have been reported during the interval period, with a conversion rate as high as $30 \%$. For unsafe LC (seriously ill or debilitated patients), cholecystostomy [16] or PTGBD [17] and interval cholecystectomy (6 to 8 weeks) were favoured, and the subsequent LCs were reported to be straightforward [16]. However, 


\begin{tabular}{|c|c|c|c|c|c|c|c|c|}
\hline Background & Grade: & $\mathbf{I}$ & II & III & IV & $\mathbf{V}$ & VI & Total \\
\hline & Cases: & 123 & 7 & $13(1)$ & 53 & $35(5)$ & $29(12)$ & $260(18)$ \\
\hline \multicolumn{2}{|c|}{ Acute cholecystitis } & 2 & 2 & 1 & 17 & $12(2)$ & $18(9)$ & $52(11)$ \\
\hline \multicolumn{2}{|c|}{ s/p PTGBD } & 1 & & & 9 & $7(2)$ & $9(4)$ & $26(6)$ \\
\hline \multicolumn{2}{|c|}{ s/p ENBD } & & & & 1 & $1(1)$ & 2 & $4(1)$ \\
\hline \multicolumn{2}{|c|}{ s/p EST } & & 1 & & & $4(1)$ & $1(1)$ & $6(2)$ \\
\hline \multicolumn{2}{|c|}{ any biliary drainage case $(\%)$} & $1(50 \%)$ & $1(50 \%)$ & $0(0 \%)$ & $9(53.0 \%)$ & $8(66.7 \%)$ & $10(55.6 \%)$ & $29(55.8 \%)$ \\
\hline \multicolumn{2}{|c|}{ Chronic cholecystitis } & 121 & 5 & $12(1)$ & 36 & $23(3)$ & $11(3)$ & $208(7)$ \\
\hline \multicolumn{2}{|c|}{ s/p PTGBD } & 2 & & $4(1)$ & 6 & $7(2)$ & 1 & $20(3)$ \\
\hline \multicolumn{2}{|c|}{ s/p ENBD } & 11 & 1 & 2 & 6 & 3 & $2(1)$ & $25(1)$ \\
\hline \multicolumn{2}{|c|}{ s/p EST } & 21 & & 2 & 9 & $5(1)$ & 1 & $38(1)$ \\
\hline \multicolumn{2}{|c|}{ any biliary drainage case $(\%)$} & $23(19.0 \%)$ & $1(20.0 \%)$ & $6(50.0 \%)$ & $13(36.1 \%)$ & $12(52.2 \%)$ & $3(27.3 \%)$ & $58(27.9 \%)$ \\
\hline \multicolumn{2}{|c|}{ Cystic duct stone } & 4 & 2 & & 2 & 5 & $1(1)$ & $14(1)$ \\
\hline \multicolumn{2}{|c|}{ Mirrizi's syndrome } & & & & & 2 & $2(1)$ & $4(1)$ \\
\hline \multicolumn{2}{|c|}{ GB gangrenous/necrotic } & & & & & $7(2)$ & $6(4)$ & $13(6)$ \\
\hline \multicolumn{2}{|c|}{ GB empyema } & & & $1(1)$ & 6 & $11(1)$ & $8(3)$ & $26(5)$ \\
\hline \multicolumn{2}{|c|}{ Calot's triangle necrosis } & & & & & 2 & $2(1)$ & $4(1)$ \\
\hline \multicolumn{2}{|c|}{ Fibrotic change of HDL } & & & & & & $6(6)$ & $6(6)$ \\
\hline \multicolumn{2}{|c|}{ Biliary pancreatitis } & 27 & 1 & 1 & 12 & 9 & 3 & 53 \\
\hline \multicolumn{2}{|c|}{ ERCP } & 35 & 4 & 4 & 13 & 13 & 19 & 88 \\
\hline \multicolumn{2}{|c|}{ CBD stone } & 41 & 1 & 3 & 14 & 13 & 4 & 76 \\
\hline \multicolumn{2}{|c|}{ (s/p EST) } & 23 & & 2 & 9 & 9 & 3 & 46 \\
\hline \multicolumn{2}{|c|}{ Liver fibrosis } & 6 & 1 & 1 & 2 & & & 10 \\
\hline \multicolumn{2}{|c|}{ Liver cirrhosis } & 15 & 1 & 2 & 5 & 2 & $7(4)$ & $32(4)$ \\
\hline
\end{tabular}

Note: (): Number of conversions to open cholecystectomy; PTGBD: percutaneous transhepatic gall bladder drainage; ENBD: endoscopic nasobiliary drainage; EST: endoscopic sphincterotomy; GB: gallbladder; HDL: hepatoduodenal ligament; ERCP: endoscopic retrograde cholangiopancreatography

Table 2: Patient's background and Chang's grading of gallbladder inflammation.

\begin{tabular}{|c|c|c|c|c|c|c|c|c|c|c|}
\hline \multirow{2}{*}{$\begin{array}{c}\text { Lapse groups } \\
\text { (days) }\end{array}$} & \multirow{2}{*}{$\begin{array}{l}\text { Grade: } \\
\text { Cases: }\end{array}$} & \multirow{2}{*}{$\frac{I}{123}$} & \multirow{2}{*}{$\begin{array}{l}\text { II } \\
7\end{array}$} & \multirow{2}{*}{$\begin{array}{c}\text { III } \\
13(1)\end{array}$} & \multirow{2}{*}{$\begin{array}{l}\text { IV } \\
53\end{array}$} & \multirow{2}{*}{$\frac{\mathbf{v}}{35(5)}$} & \multirow{2}{*}{$\begin{array}{c}\mathbf{V I} \\
29(12)\end{array}$} & \multirow{2}{*}{$\begin{array}{c}\text { Total } \\
260(18)\end{array}$} & \multicolumn{2}{|c|}{ Conversion Rate (\%) } \\
\hline & & & & & & & & & Difficult GB & Overall \\
\hline \multicolumn{2}{|l|}{$\leq 3$} & 20 & 0 & 1 & 2 & 1 & 0 & 24 & 0 & 0 \\
\hline \multicolumn{2}{|l|}{$4-7$} & 4 & 0 & 5 & 7 & $5(2)$ & $5(2)$ & $26(4)$ & 40.0 & 15.4 \\
\hline \multicolumn{2}{|l|}{$8-10$} & 16 & 2 & 0 & 3 & 5 & $4(1)$ & $30(1)$ & 11.1 & 3.3 \\
\hline \multicolumn{2}{|l|}{$11-14$} & 15 & 1 & 3 & 8 & 5 & $6(2)$ & $38(2)$ & 18.2 & 5.3 \\
\hline \multicolumn{2}{|l|}{$15-21$} & 17 & 0 & 0 & 6 & $8(1)$ & $6(2)$ & $37(3)$ & 21.4 & 8.1 \\
\hline \multicolumn{2}{|l|}{$22-28$} & 11 & 1 & 1 & 3 & $2(1)$ & 0 & $18(1)$ & 50.0 & 5.6 \\
\hline \multicolumn{2}{|l|}{$\geq 29$} & 40 & 3 & $3(1)$ & 24 & $9(1)$ & $8(5)$ & $87(6)$ & 35.3 & 6.9 \\
\hline \multicolumn{2}{|c|}{ P-value ${ }^{a}$} & & & & & & & & 0.649 & 0.445 \\
\hline
\end{tabular}

Note: (): Number of conversions to open cholecystectomy. ${ }^{\mathrm{a}}$ : Using a $\mathrm{X}^{2}$ test

Table 3: Patient's gallbladder inflammation grading by lapse group.

the author experienced his first CBD injury in a cholecystostomy and interval OC case with severe, dense, fibrotic change around the Calot's triangle and HDL areas, and then realized that interval cholecystectomy is not a panacea.

In the current series, 43 cases of gangrene, necrosis, or empyema were encountered; ensuing fibrotic changes were apparently inevitable even after an interval delay. There is no absolute promise that inflammation will be spontaneously resolved after conservative treatment and that the operation will then be straightforward. Rattner et al. [13] stated that there is little evidence to show that a cooling-off period will reduce the rate of conversion to OC. Currently, the literature contains no strictly randomized studies on the interval cholecystectomy, nor on the outcome of sustained progression of CBD inflammation to necrosis or fibrosis during the interval and the ensuing risk of $\mathrm{CBD}$ injury as the author experienced, because there is no proper inflammation parameter for such kind of data recording or comparative study.
Generally, in the first 48 to 72 hours of symptoms, the tissue planes are edematous, and Calot's structures can be identified without much difficulty. After 72 hours, the tissue becomes more friable and separates less well; therefore, the important structures are less likely to be clearly seen [16] . Sternberg [18] stated that "a delay of operation, particularly by laparoscopy, may be harmful because fibroblastic cells infiltrate by Day 9 , creating a dense tissue reaction that soon results in variation of subacute cholecystitis and the development of fibrous 'chronic' histopathologic features". Schrenk et al. [19] in an analysis of 1300 patients, indicated that it is the dense scarring at Calot's triangle that most often results in conversion or injury. This dense scarring occurs in the "late" phase of acute cholecystitis and really represents a subacute or more chronic form of cholecystitis. If repeated attacks of cholecystitis have preceded an acute episode, fibroblastic cells will have deposited fibrous tissue, resulting in a gallbladder contracted to a small size, with a very dense fibrous reaction in Calot's triangle. [20] Ishizaki et al. [15] reported their results of 1339 cases, which might support the findings of 


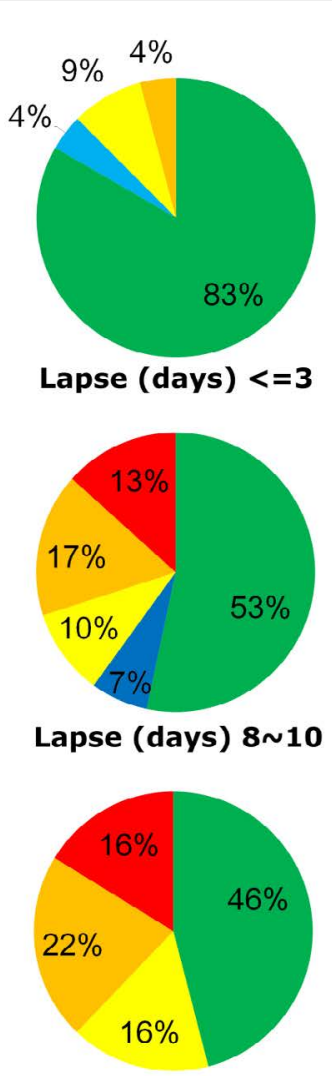

Lapse (days) 15 21

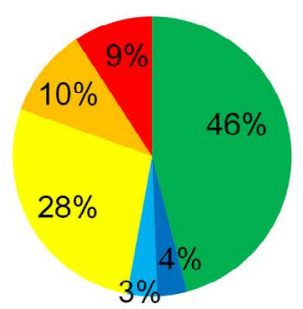

Lapse (days) $>=29$
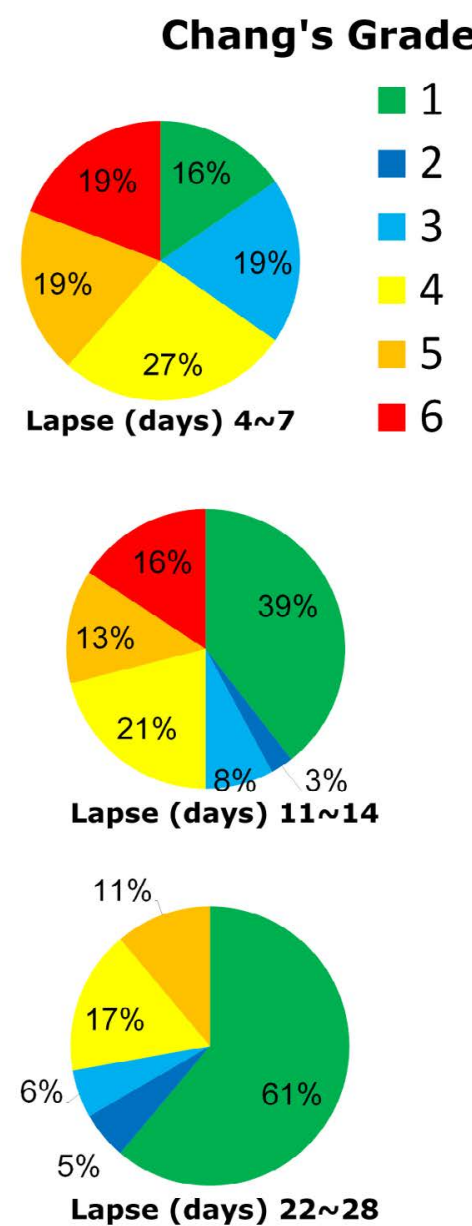

Figure 1: Detailed graph of the GB inflammation grading of each lapse group. Even after more than 1 week, inflammation grading may not be worse may not be worse than in 4-7 days lapse group. No significant difference was found between the lapse groups in terms of difficult GB, except for the $\leq 3$-day group.

these three reports [18-20]. Their conversion rate increased from $5.3 \%$ in $1993-1999$ to $10.6 \%$ in $2000-2004$. The most frequent reasons for conversion were severe inflammation or dense adhesions $(4.7 \%, \mathrm{n}=55)$, haemorrhage $(1.3 \%, \mathrm{n}=15)$, and bile duct injuries $(0.93 \%, \mathrm{n}=11)$ in 1179 patients. They routinely performed elective, interval LC 2-4 weeks later, after the administration of antibiotics or PTGBD; they did no emergency surgeries. Even 2-4 weeks after biliary decompression, 5.6\% $([55+11] / 1179)$ of the inflammation may proceed to a fibrotic state that causes difficult GB, subsequent conversion, and bile duct injuries. The overall conversion rates were similar for the author's (prompt policy: 6.9\%) and the Ishizaki et al. (interval elective policy: $7.5 \%$ ) groups. Interval elective policy did not reduce the conversion rate, which was the same as in other reports $[4,5,15,17,21]$.

Inflammation severity and technical difficulty are not significantly increased to the lapse: Different opinions and

\begin{tabular}{|c|c|c|c|c|c|c|c|}
\hline Lapse & Grade: & $\begin{array}{c}\text { I+ II + III } \\
+ \text { IV }\end{array}$ & $V+V I$ & & Fisher's & & $95 \%$ \\
\hline (days) & Cases: & $196(1)$ & $64(17)$ & P-value & $\begin{array}{c}\text { Exact } \\
\text { test }\end{array}$ & $\begin{array}{l}\text { Odds } \\
\text { ratio }\end{array}$ & $\begin{array}{c}\text { Confidence } \\
\text { Interval }\end{array}$ \\
\hline \multicolumn{2}{|c|}{$<3$} & 23 & 1 & 0.039 & 0.012 & 8.376 & $1.108-63.315$ \\
\hline \multicolumn{2}{|c|}{$>3$} & $173(1)$ & $63(17)$ & & & & \\
\hline \multicolumn{2}{|c|}{$<7$} & 39 & $11(4)$ & 0.633 & 0.717 & 1.197 & $0.572-2.504$ \\
\hline \multicolumn{2}{|c|}{$>7$} & $157(1)$ & $53(13)$ & & & & \\
\hline \multicolumn{2}{|c|}{$<10$} & 60 & $20(5)$ & 0.924 & 1.000 & 0.971 & $0.528-1.786$ \\
\hline \multicolumn{2}{|c|}{$>10$} & $136(1)$ & $44(12)$ & & & & \\
\hline \multicolumn{2}{|c|}{$<14$} & 87 & $31(7)$ & 0.572 & 0.665 & 0.850 & $0.483-1.496$ \\
\hline \multicolumn{2}{|c|}{$>14$} & $109(1)$ & $33(10)$ & & & & \\
\hline \multicolumn{2}{|c|}{$<21$} & 110 & $45(10)$ & 0.046 & 0.056 & 0.540 & $0.295-0.990$ \\
\hline \multicolumn{2}{|c|}{$>21$} & $86(1)$ & $19(7)$ & & & & \\
\hline \multicolumn{2}{|c|}{$<28$} & 126 & $47(11)$ & 0.178 & 0.222 & 0.651 & $0.348-1.219$ \\
\hline \multicolumn{2}{|c|}{$>28$} & $70(1)$ & $17(6)$ & & & & \\
\hline
\end{tabular}

Note: (): Number of conversions to open cholecystectomy

Table 4: Statistical comparison of difficult gallbladder by lapse days.

conclusions about surgical timing have been published: [1] the timing of urgent laparoscopic cholecystectomy has no impact on the conversion rate [22,23], [2] the most important predictor of the success of the attempted laparoscopic cholecystectomy is the timing of surgery [13], and [3] it is the severity of the disease rather than the timing of the surgery that probably predicts complications and conversions $[20,24]$. It is not absolutely a matter of the lapse from the onset of acute symptoms that should determine whether urgent or delayed surgery is advisable. Morbidity and mortality for acute cholecystitis seem to be determined by the degree of acute and chronic illness present at the time of diagnosis, and neither more experienced surgeons nor additional advances in laparoscopic technology is likely to dramatically affect results [25]. Efforts to improve outcomes should therefore focus on better and earlier identification of patients for surgery.

Our data clearly showed that most of the inflamed tissue in all the different lapse groups, even after more than a 1-week lapse, was not densely fibrotic (<Grade IV). In some patients with severe inflammation, such as empyema, gangrene, or necrosis of the GB and Calot's triangle, the structures in the Calot's triangle area were still not involved, and were soft and identifiable; therefore, LC was feasible with careful manipulation. This is the first report to show that inflammation grading distribution in terms of the lapse time, and that a majority of the cases were easily manageable (62-96\%). Even in groups with a lapse longer than 1 week (8-10 and 11-14 days), which are beyond the current early $(<3$ days or 1 week) policy, $[4,5]$ neither the incidence of difficult GB (30\% and $29 \%$ ) nor the conversion rate (difficult GB groups $11 \%$ and $18.2 \%$, overall $3.3 \%$ vs. $5.3 \%$ ) showed a tendency to increase when compared with the 4-7 days lapse group, and immediate LC is not contraindicated. There were also no significant differences in conversion rates or the incidence of difficult GB in each lapse group.

Surgery in the $>14$-day lapse groups was much more difficult because of Calot's triangle necrosis, abscesses, frozen CBDs, and CBD necrosis or fibrosis; however, we were unable to show a significant difference between the $\leq 14$-day and $>14$-day lapse groups as well. Misawa et al. [26] modified our grading system by scoring the severity of inflammation of Calot's triangle. It may be possible to show a significant difference in a large-scale study in terms of the lapse in the difficult GB group with this modified scoring system and to determine the predictive parameters of the inflammation.

The author agrees with Estes et al. [20] that the degree and character 


\begin{tabular}{|c|c|c|c|c|c|c|c|c|c|c|c|}
\hline \multirow{2}{*}{$\begin{array}{l}\text { Lapse } \\
\text { (days) }\end{array}$} & \multirow{2}{*}{$\begin{array}{l}\text { Grade: } \\
\text { Cases: }\end{array}$} & \multirow{2}{*}{$\begin{array}{c}I \\
123\end{array}$} & \multirow{2}{*}{$\begin{array}{l}\text { II } \\
7\end{array}$} & \multirow{2}{*}{$\begin{array}{c}\text { III } \\
13(1)\end{array}$} & \multirow{2}{*}{$\begin{array}{l}\text { IV } \\
53\end{array}$} & \multirow{2}{*}{$\begin{array}{c}\mathrm{V} \\
35(5)\end{array}$} & \multirow{2}{*}{$\begin{array}{c}\text { VI } \\
29(12)\end{array}$} & \multirow{2}{*}{$\begin{array}{c}\text { Total } \\
260 \text { (18) }\end{array}$} & \multicolumn{2}{|c|}{ Conversion } & \multirow[t]{2}{*}{ Fisher's exact test } \\
\hline & & & & & & & & & No & Yes & \\
\hline \multicolumn{2}{|c|}{$\leq 3$} & 20 & 0 & 1 & 2 & 1 & 0 & 24 & 24 & 0 & 0.388 \\
\hline \multicolumn{2}{|c|}{$>3$} & 103 & 7 & $12(1)$ & 51 & $34(5)$ & $29(12)$ & $236(18)$ & 218 & 18 & \\
\hline \multicolumn{2}{|c|}{$\leq 7$} & 24 & 0 & 6 & 9 & $6(2)$ & $5(2)$ & $50(4)$ & 46 & 4 & 0.757 \\
\hline \multicolumn{2}{|c|}{$>7$} & 99 & 7 & $7(1)$ & 44 & $29(3)$ & $24(10)$ & $210(14)$ & 196 & 14 & \\
\hline \multicolumn{2}{|c|}{$\leq 10$} & 40 & 2 & 6 & 12 & $11(2)$ & $9(3)$ & $80(5)$ & 75 & 5 & 1.000 \\
\hline \multicolumn{2}{|c|}{$>10$} & 83 & 5 & $7(1)$ & 41 & $24(3)$ & $20(9)$ & $180(13)$ & 167 & 13 & \\
\hline \multicolumn{2}{|c|}{$\leq 14$} & 55 & 3 & 9 & 20 & $16(2)$ & $15(5)$ & $118(7)$ & 111 & 7 & 0.630 \\
\hline \multicolumn{2}{|c|}{$>14$} & 68 & 4 & $4(1)$ & 33 & $19(3)$ & $14(7)$ & $142(11)$ & 131 & 11 & \\
\hline \multicolumn{2}{|c|}{$\leq 21$} & 72 & 3 & 9 & 26 & $24(3)$ & $21(7)$ & $155(10)$ & 145 & 10 & 0.805 \\
\hline \multicolumn{2}{|c|}{$>21$} & 51 & 4 & $4(1)$ & 27 & $11(2)$ & $8(5)$ & $105(8)$ & 97 & 8 & \\
\hline \multicolumn{2}{|c|}{$\leq 28$} & 83 & 4 & 10 & 29 & $26(4)$ & $21(7)$ & $18(1)$ & 162 & 11 & 0.612 \\
\hline \multicolumn{2}{|c|}{$>28$} & 40 & 3 & $3(1)$ & 24 & $9(1)$ & $8(5)$ & $87(6)$ & 80 & 7 & \\
\hline
\end{tabular}

Note: (): Number of conversions to open cholecystectomy

Table 5: Statistical comparison of conversion by lapse days.

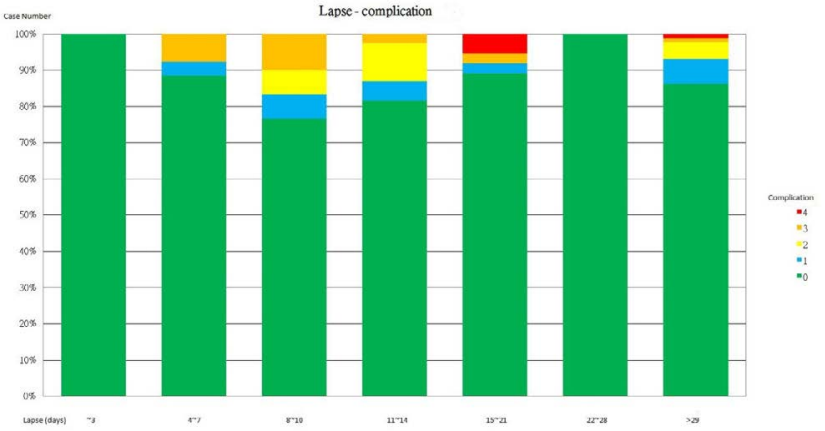

Figure 2: Bar graph of complication in each lapse group. There was no significant difference between any lapse groups or between any two different lapse groups. Green: no complication; Blue: non-bile related; Yellow: minor bile leak, but no need of intervention; Brown: bile leak needed ENBD decompression; Red: CBD injury.

of these histological changes are proportional to the severity and duration of the initial insult and to the interval of time until the organ is removed. A majority of our cases in different lapse groups showed no severe inflammation, and time is not the sole issue. Our difficult GB (Grades V and VI) comprised from $11 \%$ to $38 \%$ in the $>3$-days lapse groups (Figure 1), which is compatible with the published data of readmission, $[2,4,5]$ and to the emergency cholecystectomy rate attributed to persistent or progressive initial inflammation during the interval waiting period. This is the subset of patients for whom disease severity is proportional to the lapse time. Current parameters of deciding the optimal operation timing depend on conversion rate, operation time, blood loss, length of hospital stay, medical costs, incidence of CBD injury, complication rate, and the risk of repeat cholecystitis in terms of acute, chronic cholecystitis or a dichotomized time period. None of the published articles on LC show the data of inflammatory patterns and severity around the GB, the incidence of necrosis and fibrosis in Calot's triangle and the CBD, or operation difficulty in terms of different lapses. Current "time-based" decision methodology by randomized study of dichotomizing the lapse in terms of conventional parameters to determine surgical timing may involve a major error. An alternative policy or different parameters may be needed to identify the subset of difficult GB patients. Nevertheless, from current results the policy of the "golden time rule" or early surgery is equally applicable for both the simple and the difficult GB groups.

Vision of the goal: Cholecystectomy should be done prior to formation of LC land mine, i.e., cicatrix formation:

The author agrees with a recent proposal in some articles $[17,24]$ that conversion to OC must not be considered a failure. From this viewpoint, the risk of iatrogenic $\mathrm{CBD}$ injury becomes the most paramount parameter for determining optimal timing for surgery for symptomatic GB disease. Chronological inflammatory changesfrom acute edematous $\mathrm{GB}$ to its final phases of $\mathrm{CBD}$ necrosis and fibrosis-may be encountered in current daily practice. Inflammation around Calot's triangle can impair visualizing the ductal anatomy and the cystic artery[16]. The author has experienced all severe forms of inflammation in the current series and would like to stress that anatomic distortion after fibrotic change is the major contributing factor for the misconception that leads to CBD injury. Misawa et al. [26] in a meticulous retrospective study analyzed 34 cases of CBD injury and found that the mistake involved misidentifying the CBD as the cystic duct in $53 \%$ of the cases. Their class III injuries (6 cases) showed the "mildest" GB inflammation, and were mentioned as unavoidable by experienced surgeons; the operators identified the CBD as the cystic duct and saw it clearly. This is the "classic" phenomenon, [17,27] the misperception $[26,27]$ that easily occurs when the CBD adheres closely to the GB and the cystic duct is partially or completely hidden from view by the infundibulum (hidden cystic duct) [27] after a chronic fibrotic process. Other than the hidden cystic duct, the author often encountered ultra-shortened and barely or completely disappeared cystic ducts in the current series. The above phenomena are like a land mine of LC that injures both the patient and the surgeon. Only one of the author's patients died, a patient whose condition became critical because of repeated delays of surgery. The author realizes that the simplest and easiest way is to prevent the development of cicatrix formation as much as possible in every case, either by index admission LC, $[22,24]$ or by immediate $[13,16,17]$ or urgent LC $[20,23]$ at its initial edematous stage. The inflammation processes in unresolved cases, 20 $30 \%$ in the current study and others, $[2,4,5]$ may continue during the interval waiting period. One hundred percentage of no improvement were predicted in our acute non-fibrotic cases of grade $\mathrm{V}$ and VI groups [28]. Delay and the interval policy by medical personnel are the major 
Citation: Chang YC (2017) Is it Justified to use the Lapse Day as a Decision Maker of Laparoscopic Cholecystectomy for Symptomatic Gall Bladder Stone Disease. Hepatol Pancreat Sci 1: 105.

causes of dense fibrosis and distortion of the anatomy, which contribute to classic iatrogenic CBD injuries and are preventable by early surgery.

\section{Conclusion}

Various inflammation grades were shown to be non-significant in each lapse group irrespective of the lapse time except in the $\leq 3$ days group. The majority of current patients $(<$ Grade IV, simple GB) were easily manageable irrespective of the different lapse times. Less than a third of the patients who develop a difficult GB needed early LC to avert subsequent progression of dense fibrosis, surgical land mine, if delayed. Dichotomized lapse determination for LC without considering intraoperative inflammation status is not justified.

\section{Conflict of Interest}

The author of this manuscript has no conflicts of interest to disclose.

\section{References}

1. van der Linden W, Sunzel H (1970) Early versus delayed operation for acute cholecystitis. Am J Surg 120: 7-13.

2. Jarven HJ, Hastbacka J (1980) Early cholecystectomy for acute cholecystitis. Ann Surg 191: 501-505.

3. Norrby S, Herlin P, Holmin T, Sjodhl, Tagesson C (1983) Early or delayed cholecystectomy in acute cholecystitis? A clinical trial. Br J Surg 70: 163-165.

4. Lau H, Lo CY, Patil NG, Yuen WK (2006) Early versus delayed-interval laparoscopic cholecystectomy for acute cholecystitis: A meta-analysis. Surg Endosc 20: 82-87.

5. Gurusamy K, Samraj K, Gluud C, Wilson E, Davidson BR (2010) Meta-analysis of randomized controlled trials on the safety and effectiveness of early versus delayed laparoscopic cholecystectomy for acute cholecystitis. Br J Surg 97: $141-150$

6. Chang YC (2005) A proposed inflammation grading system for laparoscopic cholecystectomy. Hepatogastroenterology 52: 33-36.

7. Martin IG, Dexter SPL, Marton J, Gibson J, Asker J, et al. (1995) Fundus-first laparoscopic cholecystectomy. Surg Endosc 9: 203-206.

8. Fabiani P, lovine L, Katkhouda J (1993) Dissection du triangle de Calot par voie coelioscopique. Presse Med 22: 535-537.

9. Nagai H, Kondo Y, Yasuda T, Kasahara K, Kanazawa K (1993) An abdominal wall-lifting method of laparoscopic cholecystectomy without peritoneal insufflation. Surg Laparosc Endosc 3: 175-179.

10. Essenhigh DM (1966) Management of acute cholecystitis. Br J Surg 53: 10321038.

11. Golden L, Morgan J, Kay J (1948) Acute cholecystitis. Gastroenterology 11: 318-325

12. Edlung Y, Olsson O (1961) Acute cholecystitis: Its etiology and course, with special reference to the timing of cholecystectomy. Acta Chir Scand 120: 474494

13. Rattner DW, Ferguson C, Warshaw AL (1993) Factors associated with successful laparoscopic cholecystectomy for acute cholecystitis. Ann Surg 217 233-236.

14. Strasberg SM (2008) Acute calculous cholecystitis. N Engl J Med 358: 28042811.

15. Ishizaki Y, Miwa K, Yoshimoto J, Sugo H, Kawasaki S (2006) Conversion of elective laparoscopic to open cholecystectomy between 1993 and 2004. Br J Surg 93: 987-991.

16. Litwin DEM, Cahan MA (2008) Laparoscopic cholecystectomy. Surg Clin N Am 88: $1295-1313$.

17. Elwood DR (2008) Cholecystitis. Surg Clin N Am 88: 1241-1252.

18. Sternberg SS, ed. Diagnostic Surgical Pathology, 2nd Ed, Vol 2, New York: Raven Press, 1994:1587.

19. Schrenk P, Woisetschlager R, Wayland Wu (1995) Laparoscopic cholecystectomy. Cause of conversion in 1,300 patients and analysis of risk factors. Surg Endosc 9: 25-8.

20. Estes N, McElhinney C, Estes MA, Opie H, Johnson M (1996) Acute cholecystitis treated urgently by nonselective laparoscopic cholecystectomy. Am Surgeon 62: 598-602.

21. Li VKM, Yum JLK, Yeung YP (2010) Optimal timing of elective laparoscopic cholecystectomy after acute cholangitis and subsequent clearance of choledocholithiasis. Am J Surg 200: 483-488.

22. Knight JS, Mercer SJ, Somers SS, Walters AM, Sadek SA, et al. (2004) Timing of urgent laparoscopic cholecystectomy does not influence conversion rate. $\mathrm{Br}$ J Surg 91: 601-604.

23. Wang YC, Yang HR, Chung PK, Jeng LB, Chen RJ (2006) Urgent laparoscopic cholecystectomy in the management of acute cholecystitis: timing does not influence conversion rate. Surg Endoc 20: 806-808.

24. Young AL, Cockbain AJ, White AW, Hood A, Menon KV, et al. (2010) Index admission laparoscopic cholecystectomy for patients with acute biliary symptoms: results from a specialist center. HPB 12: 270-276.

25. Bender JS, Duncan MD, Freeswick PD, Harmon JW, Magnuson TH (2002) Increased laparoscopic experience does not lead to improved results with acute cholecystitis. Am J Surg 184: 591-595.

26. Misawa T, Saito R, Shiba H, Son K, Futagawa Y, et al. (2006) Analysis of bile duct injuries (Stewart-Way classification) during laparoscopic cholecystectomy. J Hepatobiliary Pancreat Surg 13: 427-434.

27. Strasberg SM, Eagon CJ, Drebin JA (2000) The "hidden cystic duct" syndrome and the infundibular technique of laparoscopic cholecystectomy-the danger of the false infundibulum. J Am Coll Surg 191: 661-667.

28. Chang YC (2016) A predictive analysis of interval cholecystectomy according to GB inflammation status during laparoscopic cholecystectomy. Ann Surg Hepatol 21: 59-77. 